\title{
Detection of 793/B serotype of infectious bronchitis virus in tissue sample by indirect immunoperoxidase assay
}

\author{
Mehrdad Shamsaddini-Bafti • M. Vasfi-Marandi • \\ R. Momayez • R. Toroghi • S. A. Pourbakhsh $\cdot$ R. Salari • \\ H. Tabrizchi
}

Received: 9 December 2011 / Accepted: 19 September 2012 /Published online: 29 September 2012

(C) Springer-Verlag London 2012

\begin{abstract}
The indirect immunoperoxidase (IIP) assay was compared with the reverse transcription-polymerase chain reaction (RT-PCR) for detection of 793/B serotype of infectious bronchitis virus in tissues samples collected from experimentally infected chickens. This technique was optimized in specific pathogen-free (SPF)-embryonated chicken eggs and broiler chickens inoculated with the Iranian IR/773/2001 strain of 793/B serotype The trachea, lung, kidney, and cecal tonsil tissue samples from experimentally infected chicken embryos and chickens were collected in order to prepare tissue sections in IIP assay and to detect in RT-PCR. The sensitivity and specificity values of IIP assay were, respectively, 83 and $84 \%$, and the positive and negative prediction values were 71 and $91 \%$ when compared with RT-PCR.
\end{abstract}

Keywords Infectious bronchitis virus - 793/B serotype Immunoperoxidase assay $\cdot$ RT-PCR

\footnotetext{
M. Shamsaddini-Bafti $(\bowtie)$

Razi Vaccine \& Serum Research Institute, Kerman Branch,

km. 17th of Joupar, Kerman Rd,

Kerman, Iran, Post. Box: 76175-359

e-mail: mshdin2002@yahoo.com

M. Vasfi-Marandi

Faculty of Veterinary Medicine, University of Tehran,

Tehran, Iran

R. Momayez $\cdot$ R. Toroghi $\cdot$ S. A. Pourbakhsh

Razi Vaccine \& Serum Research Institute,

Karaj, Iran

R. Salari

Faculty of Sciences, University of Tehran,

Tehran, Iran

H. Tabrizchi

Faculty of Medicine, University of Kerman,

Kerman, Iran
}

\section{Introduction}

Infectious bronchitis (IB) is a significant viral disease of poultry worldwide and caused by infectious bronchitis virus (IBV). This disease has caused high economic losses in the Iranian poultry industry (Shoushtari et al. 2008; VasfiMarandi and Bozorgmehrifard 2001). IBV belongs to group III of the genus Coronavirus of Coronaviridae family. The nucleocapsid (N) protein of IBV is closely associated with the genomic RNA, and has highly conserved amino acid and nucleotide sequences. The spike glycoprotein (S) is anchored in the viral envelope and is post-translationally cleaved into two proteins designated S1 and S2. In contrast to the $\mathrm{N}$ protein, the $\mathrm{S}$ protein is very diverse in terms of both nucleotide sequence and deduced primary protein structure (Kant et al. 1992). The presence of IBV is commonly determined by the inoculation of suspected tissue samples material into embryonated chicken eggs for observation the specific lesions of embryos by the IBVs, followed by serological methods in chickens. IBV also may be detected directly in tissue of infected birds by immunohistochemical (IHC) staining and reverse transcription-polymerase chain reaction (RT-PCR) techniques (Cavanagh and Naqi 2003; De Wit 2000; Swayne et al. 1998). The immunoperoxidase (IP) assay has been successfully used to determine the presence of antigen in tissue sections in most diagnostic laboratories. The IP assay can be performed by direct (DIP) and indirect (IIP) methods. The IIP assay is more sensitive than DIP, but depends on the type selection of reagents. The IIP assay is a reliable and rapid diagnostic assay (Dabbas 2002; Chauhan 1995; Hayat 2002; Levinson and Jawetz 1998). Complexes of antigen and antibody are observable by using enzyme substrate which makes a colorful reaction. The slides prepared according to the IP assay, such as histology and pathology slides, are storable for long time, thus, it is possible to carry out IP assay for retrospective analysis on 
paraffin-embedded tissue sections. The main problem of this technique is the existence of endogenous peroxidase in cells such as white blood cells that can show false-positive results. To solve this problem, the activity of endogen peroxidase should be neutralized before using initial antibody.

The aim of this study is optimization of an IIP assay on paraffin-embedded tissue sections prepared from experimentally infected chickens with an Iranian 793/B serotype strain of IBV.

\section{Materials and methods}

Virus propagation The Iranian IR/773/2001 (793/B) strain of IBV, isolated at the Razi institute of Iran (Momayez et al. 2008), was used in this study. This virus was propagated in 10day-old specific pathogen-free (SPF) embryonated chicken eggs. The inoculated eggs were incubated at $37^{\circ} \mathrm{C}$ for 48 $72 \mathrm{~h}$ and infected allantoic fluids were harvested 6 days postinoculation (PI). These fluids were clarified by centrifugation at $8,000 \times g$ for $20 \mathrm{~min}$ at $4{ }^{\circ} \mathrm{C}$ for removing particulate host debris. The supernatant was collected and then the embryo infective dose $50 \%\left(\mathrm{EID}_{50}\right)$ titer was calculated according to Ried and Mounch's instruction (Swayne et al. 1998).

\section{Experimental infections}

Specific pathogen-free-embryonated chicken eggs A volume of $0.1 \mathrm{ml}$ of an Iranian IR/773/2001 (793/B) strain of IBV, H9N2 subtype of avian influenza virus, velogenic Newcastle disease virus, and virulent infectious laryngotracheitis virus (each with approximately of $10^{3} \mathrm{EID}_{50}$ ), were separately inoculated into the allantoic cavity of five 10day-old SPF-embryonated chicken eggs. Another five eggs were inoculated with uninfected allantoic fluid of SPF eggs as control group. Inoculated eggs were incubated at $37^{\circ} \mathrm{C}$ and checked twice a day. The allantoic fluid and chorioallantoic membrane (CAM) were harvested from eggs at 15, 24, 36 and $48 \mathrm{~h}$ after PI. All CAM samples were placed in $10 \%$ formalin buffer solution for $24 \mathrm{~h}$ for preparation of paraffin-embedded tissue sections.

Experimental infection in chickens Ten 22-day-old broiler chickens which were negative on ELISA for IBV were selected. Five chickens were inoculated with a volume of $0.2 \mathrm{ml}$ of IBV containing $10^{3.33}$ ELD $_{50}$ titer by oral and tracheal routs. The remaining birds were inoculated with $0.2 \mathrm{ml}$ of uninfected allantoic fluid of SPF embryonated chicken eggs and used as control group. The birds were killed and tracheae, lung, kidney, and cecal tonsil tissues were sampled in days 1, 2, 3, 4, and 5 PI. Each tissue sample was divided to two separate parts. One part was kept at $-70{ }^{\circ} \mathrm{C}$ for RT-PCR assay, and the other part was put in
$10 \%$ formaldehyde buffer solution for $24 \mathrm{~h}$ in order to prepare tissue sections for IP assay.

Preparation of paraffin-embedded tissue sections For paraffin-embedded tissue sections preparation, the samples were processed by a passage apparatus. The paraffin blocks were cut by a microtome with a 3-4- $\mu$ m thickness on the slides covered with 3-aminopropyltriethoxysilane solution. The slides were incubated at $37^{\circ} \mathrm{C}$ overnight and used in the IIP assay.

Indirect immunoperoxidase assay The IIP assay was carried out according to the instructions of Naqi (1990) and with slight modifications. The slides were incubated at $56{ }^{\circ} \mathrm{C}$ for $30 \mathrm{~min}$. After being rehydrated by ethanol, the slides were rinsed first in deionized water and then placed in Tris buffer solution (TBS $=50 \mathrm{mM}$ Tris $\mathrm{HCl}, 150 \mathrm{mM} \mathrm{NaCl}, \mathrm{pH}=7.6$ ) for $5 \mathrm{~min}$. Antigen retrial was performed by incubating the sections for $20 \mathrm{~min}$ with EDTA solution $(10 \mathrm{mM}$ Tris, $1 \mathrm{mM}$ EDTA, $\mathrm{pH}=9$ ). After $20 \mathrm{~min}$, the slides were left at room temperature (RT) and then rinsed with TBS. The tissues were encompassed using a special immunohistochemistry pen. Then, the solutions that block the endogenous peroxidase and biotin activity were added separately on the tissue sections and they were rinsed with TBS after $5 \mathrm{~min}$. A volume of $200 \mu \mathrm{l}$ of $1 / 400$ dilution of group-specific anti-IBV monoclonal antibody (anti-M and anti-S) (Naqi 1990) was added on tissue sections and incubated at $4{ }^{\circ} \mathrm{C}$ for $24 \mathrm{~h}$. Then the slides were rinsed three times in TBS for $5 \mathrm{~min}$. A volume about $200 \mu \mathrm{l}$ of anti-mouse biotin prepared in goat was added on the slides and incubated at RT for $45 \mathrm{~min}$. After rinsing with TBS as above, the peroxidase conjugated connected to streptavidin was added on the tissue sections and incubated at RT for $15 \mathrm{~min}$. To demonstrate the reaction between antibody and antigen, DAB substrate solution antibody (DakoCytomation Co., Glostrup, Denmark) was used. The slides were removed from the rinsing solution and were dried rapidly. Then, substrate solution was applied on the tissue sections and the sections were placed in RT. After being dehydrated by ethanol, the slides were rinsed first in deionized water then covered with background staining solution (methyl green or hematoxylin). The extra stains were removed by adding ethyl alcohol; finally, the slides were mounted by permanent mounting media (DakoCytomation Co., Glostrup, Denmark). The intensity of reaction of the specific monoclonal antibody against IBV in tissue sections was carried out according to Cruz-Coy et al. (1993). Scoring of reaction was detected by optical microscope in magnification 40 as follows: $(0)=$ no cell is positive, $(+1)=$ less than one positive cell, $(+2)=$ between 1 and 5 positive cells and $(+3)=$ more than 5 positive cells. Furthermore, different dilutions of antigens were analyzed and the 1:300 dilution was taken into account for primary antibody in IIP assay. 
Fig. 1 Positive reaction of group-specific monoclonal antibody and infectious bronchitis virus (IBV) on chorioallantoic membrane (left) and kidney (right) in indirect immunoperoxidase (IIP) assay and DAB is as substrate $(\times 200, \times 400)$
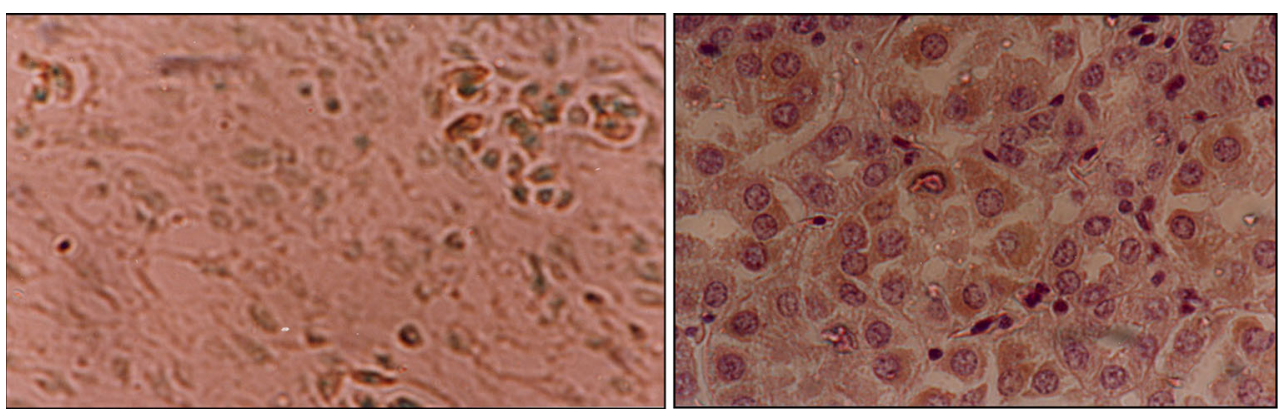

\section{RT-PCR assay}

Total RNA extraction Total RNA was extracted from the trachea, kidney, and lung tissues using the Tripure reagent (Life Technologies Inc., USA) according to the manufacturer's instructions. Briefly, $100 \mathrm{mg}$ of the tissues was homogenized with $1 \mathrm{ml}$ of Tripure. After adding $200 \mu \mathrm{l}$ of chloroform and vigorous shaking the aqueous phase was separated by centrifugation at $12,000 \times g$ for $10 \mathrm{~min}$. Total RNA in the supernatant was precipitated by adding $0.5 \mathrm{ml}$ of isopropanol and by centrifugation. After washing and drying, the RNA was dissolved in $15 \mu \mathrm{l}$ of nuclease-free water.

RT-PCR method Total RNA was subjected to reverse transcription using Moloney murine leukemia virus reverse transcriptase (Roche Co., Germany) and (S gene) specific primer (CCAAAGTGCCTTGAGGCCTGG) (AACGCCTGCACCCGTAACGTA) (480 bp) (Titan One Tube RT-PCR System) according to the manufacturer's instructions as described by Cavanagh et al. (1999). Briefly, the amplification was carried out in a $50 \mu$ reaction mixture containing $6 \mu \mathrm{l}$ of cDNA, 15 pmol of each primer,
$200 \mu \mathrm{mol} / 1 \mathrm{dNTPs}, 1.5 \mathrm{mmol} / 1 \mathrm{MgCl}_{2}$ and $1.5 \mathrm{U}$ of Taq DNA polymerase (Roche Co., Germany) in 35 cycles, each cycle consisting of $95^{\circ} \mathrm{C}$ for $1 \mathrm{~min}, 48^{\circ} \mathrm{C}$ for $1.5 \mathrm{~min}$, and $72{ }^{\circ} \mathrm{C}$ for $2 \mathrm{~min}$ with a final extension at $72^{\circ} \mathrm{C}$ for $10 \mathrm{~min}$. The amplified products were separated by electrophoresis, using a $1 \%$ agarose and stained with ethidium bromide. The amplified bands were visualized and photographed under UV illumination (UVP, Transilluminator, M20, USA).

Statistical analysis The kappa statistical method was used in this analysis. The results of RT-PCR were considered as golden standard test. The sensitivity, specificity, and positive and negative prediction values of the experiments have been compared. Furthermore, accuracy and kappa analysis were calculated by evaluating the correlation between experiments according the method described by Dhinakar et al. (1998).

\section{Results}

Indirect immunoperoxidase assay The IIP assay of experimentally infected chorioallantoic membrane, tracheae, lung,
Fig. 2 Agarose gel electrophoresis and ethidium bromide staining of RT-PCR products $(M$ marker, $C o n P$ positive control, $T$ trachea tissue and 2, 3, 4, and 5 days postinoculation (PT), Tcon trachea tissue negative control, $L$ lung tissue, Lcon lung tissue negative control, $K$ kidney tissue, Kcon kidney tissue negative control, $C T$ cecal tonsil tissue, CTcon cecal tonsil tissue negative control, $\mathrm{ConN}$ negative control)

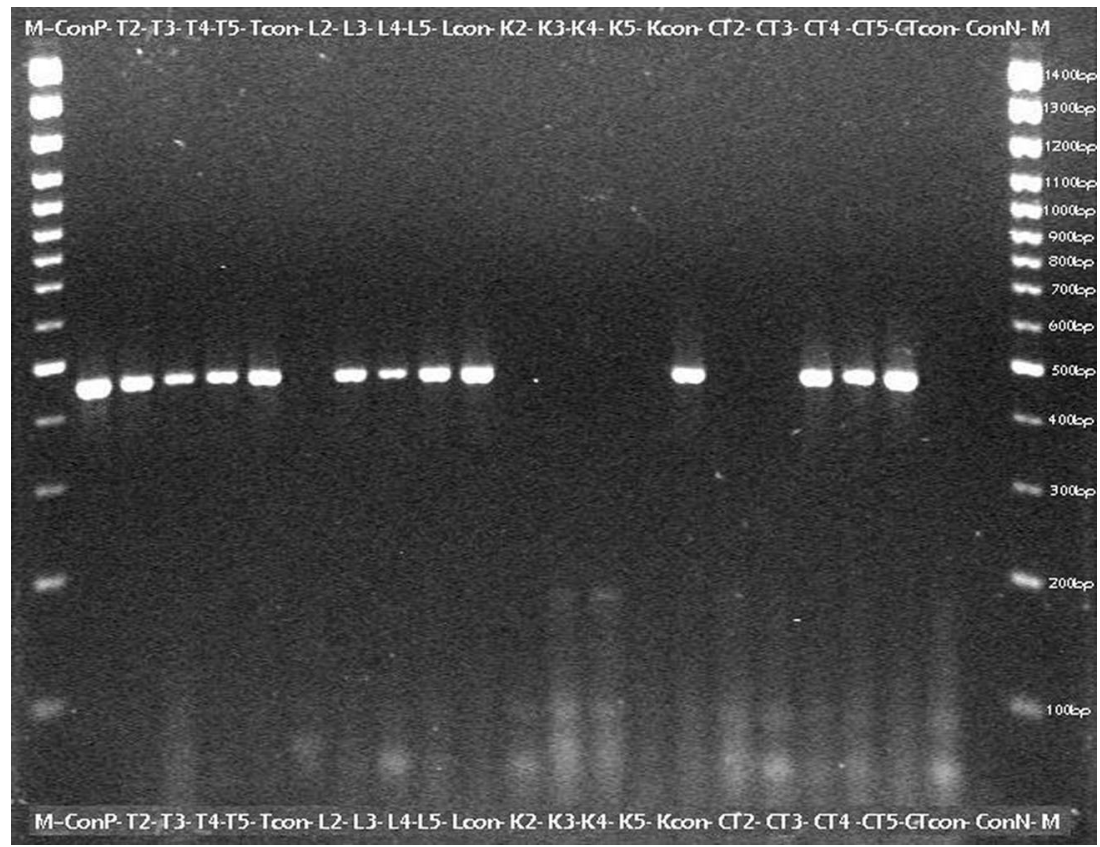


Table 1 Comparison of indirect immunoperoxidase (IIP) and RT-PCR assays in trachea (T), lung (L), kidney (K), and cecal (C) of chickens prepared from experimentally infected (inoculated) and control chickens at $1,2,3,4$, and 5 day post-inoculation (PI)
+ positive reaction, - negative reaction, $n d$ not done

\begin{tabular}{|c|c|c|c|c|c|c|c|c|c|c|c|c|c|c|c|c|}
\hline \multirow[t]{4}{*}{ PI } & \multicolumn{8}{|c|}{ Inoculated chicken } & \multicolumn{8}{|c|}{ Control chicken } \\
\hline & \multicolumn{4}{|c|}{ IIP } & \multicolumn{4}{|c|}{ RT-PCR } & \multicolumn{4}{|c|}{ IIP } & \multicolumn{4}{|c|}{ RT-PCR } \\
\hline & \multicolumn{16}{|c|}{ Test tissue } \\
\hline & $\mathrm{T}$ & $\mathrm{L}$ & $\mathrm{K}$ & $\mathrm{C}$ & $\mathrm{T}$ & $\mathrm{L}$ & K & $\mathrm{C}$ & $\mathrm{T}$ & $\mathrm{L}$ & K & $\mathrm{C}$ & $\mathrm{T}$ & $\mathrm{L}$ & K & $\mathrm{C}$ \\
\hline 1 & - & - & - & - & nd & nd & - & - & - & - & - & - & - & - & - & - \\
\hline 2 & - & - & + & + & + & + & - & - & - & - & - & - & - & - & - & - \\
\hline 3 & + & + & + & + & + & + & - & + & - & - & - & - & - & - & - & - \\
\hline 4 & + & + & + & + & + & + & - & + & - & - & - & - & - & - & - & - \\
\hline 5 & + & + & + & + & + & + & + & + & - & - & - & - & - & - & - & - \\
\hline
\end{tabular}

kidney, and cecal tonsil tissues was carried out. The IBVinfected cells were brownish orange under the optical microscope examination; whereas no reaction was observed on the tissue sections prepared from inoculation by other heterologous viruses. The 1:300 dilution of the group-specific anti-IBV monoclonal antibody was found as suitable dilution for primary antibody in IIP assay.

Since +1 reaction sometimes was observed in prepared samples in controlled chickens, the intensities of +2 and +3 were considered as positive results in IIP assay. Figure 1 shows the positive response of group-specific monoclonal antibodies of IBV antigens in IIP assay.

Experiment results of RT-PCR Thirty-eight tissue samples of trachea, lung, kidney, and cecal tonsil prepared from experimentally infected chickens were tested by RT-PCR (Fig. 2). The presence of IBV was confirmed in 12 cases, while in 26 samples, it was not confirmed. The presence of virus in days 2, 3, 4, and 5 PI was confirmed in trachea and lung. Furthermore, presence of virus in day 5 in kidney and days 3,4 , and 5 in cecal tonsil were confirmed. However, the existence of IBV in the control tissue samples on days 1, 2, 3, 4, and 5 PI was not confirmed by RT-PCR. The results of RT-PCR and IIP assays in trachea, lung, kidney, and cecal tonsil are shown in Tables 1 and 2 .

The IBV was detected in trachea and lung tissues of the inoculated birds on days 3, 4, and 5 in IIP assay; whereas, the positive response was observed in tissue section of kidney on days 2, 3, 4, and 5 in IIP assay. The presence of IBV was confirmed in cecal tonsil tissue sections on days 2 , 3,4 and 5 in IIP assay. The presence of IBV was not detected in tissue samples on days 1, 2, 3, 4, and 5 PI of PBS in IIP assays.

Overall, from total 38 sections of trachea, lung, kidney, and cecal tonsil tissues of ten infected birds tested in RTPCR only 12 samples (31\%) were positive and 26 samples (68 \%) were negative. While 14 (37\%) and 24 (63\%) samples were positive and negative respectively by IIP assay.
Statistical comparison of results Regarding the data, the sensitivity and specificity of IIP assay in comparison with RT-PCR in trachea, lung, kidney, and cecal tonsil are 83 and $84 \%$, respectively. Furthermore, the positive and negative prediction values of IIP assay were obtained 71 and $91 \%$, respectively. Accuracy of IIP assay in all tissues was $84 \%$ and kappa coefficient was $94 \%$.

\section{Discussion}

Early diagnosis of poultry diseases in chicken flocks is an important affect in disease control programs. Therefore, rapid diagnostic methods of pathogenic viruses have been developed all over the world. IHC staining techniques have been part of rapid diagnostic techniques that have been developed much more and have been used increasingly for rapid diagnosis of poultry viral diseases (Swayne et al. 1998).

The use of these techniques in retrospective studies have been applied and available for analysis of diseases in one area by using frozen or paraffin-embedded tissue sections

Table 2 Detection of infectious bronchitis virus (IBV) by indirect immunoperoxidase (IIP) and RT-PCR assays in trachea, lung, kidney, and cecal tissues of inoculated and control chickens at 1,2, 3, 4, and 5 day post-inoculation (PI) (a: tissue with positive reaction and b: total tissues)

\begin{tabular}{llllll}
\hline PI & \multicolumn{2}{l}{ Inoculated chicken } & & \multicolumn{2}{l}{ Control chicken } \\
\cline { 2 - 3 } \cline { 6 - 7 } \cline { 6 - 7 } & IIP & RT-PCR & & IIP & RT-PCR \\
\hline 1 & $0^{\mathrm{a} / 4^{\mathrm{b}}}$ & $0 / 2$ & & $0 / 4$ & $0 / 4$ \\
2 & $2 / 4$ & $2 / 4$ & & $0 / 4$ & $0 / 4$ \\
3 & $4 / 4$ & $3 / 4$ & & $0 / 4$ & $0 / 4$ \\
4 & $4 / 4$ & $3 / 4$ & & $0 / 4$ & $0 / 4$ \\
5 & $4 / 4$ & $4 / 4$ & & $0 / 4$ & $0 / 4$ \\
Total (percent) & $14 / 20$ & $12 / 18$ & & $0 / 20$ & $0 / 20$ \\
& $(70 \%)$ & $(66 \%)$ & & $(0 \%)$ & $(0 \%)$ \\
\hline
\end{tabular}


(Fitzgerald et al. 1994). Some researchers have used these techniques in diagnosis of other poultry viral diseases, such as Birnavirus, Paramyxovirus, and Orthomyxoviruses (Guy et al. 1997; Liu et al. 2000; Lockaby et al. 1993; McNulty et al. 1990; Shamsaddini-Bafti et al. 2002; Smyth et al. 1993; Swayne et al. 1996).

Bhattacharjee et al. (1994); Owen et al. (1991); De Wit (2000); Chen et al. (1996), and Nakamura et al. (1991) have used IHC techniques for rapid diagnosis of IBV antigens. Owen et al. (1991) diagnosed the presence of IBV with indirect immunofluorescence and IIP assays in the mucous and under mucous of trachea, kidney, and cecal tonsil. They observed the presence of virus in the histocyte and lymphocyte cells.

In this study, IIP assay was used on paraffin-embedded tissue sections for diagnosis of IBV, and the competency of these techniques was assisted by RT-PCR assay. For routine usage of IHC techniques, these methods should be standardized. Therefore, an experimental infection was carried out in 6-week-old chickens. Besides, for getting suitable dilution of antibodies, an experimental infection was carried out in SPF chicken eggs. Determination of these dilutions was repeated in the chickens under the experiments. The IIP and RT-PCR assays were carried out on trachea, lung, kidney, and cecal tonsil tissues on the days 1, 2, 3, 4, and 5 PI (Tables 1 and 2). There was high correlation between the results of RT-PCR and IIP assays.

Naqi (1990) used IP assay for diagnosis of IBV, identifying the virus within $15 \mathrm{~h}$ PI in chorioallantoic membrane. Swayne et al. (1998) used IP assay with other diagnostic assays for assessment of IBV pathogenesis. They reported that IP assay is an acceptable, sensitive, reliable and economic technique that is simultaneously capable of diagnosis of the presence of antigens on tissue samples and analysis of cells constructions.

Handberg et al. (1999) reported that the competency of IBV diagnosis is $82 \%$ with RT-PCR in inoculated chickens. While this value was nearly $60 \%$ in the IIP assay. Chen et al. (1996) detected the IBV antigens in the kidney tissue after 4 days with IIP assay.

In this study, sensitivity, specificity, and positive and negative prediction value of IIP assay by using monoclonal antibodies against conserved section of $\mathrm{S}$ and $\mathrm{M}$ of IBV on paraffin-embedded tissue section from experimentally infected samples are $83,84,71$, and $91 \%$, respectively. In addition, the accuracy of this experiment with RT-PCR was $96 \%$ that shows complete conformity. Regarding reaction intensity, monoclonal antibodies anti-S and M of IBV were used for increasing sensitivity and specificity of IIP assay for IBV antigens on tissue sections. Using IHC techniques, it is recommended for detecting of IBV antigens in the tissues especially in trachea and lung tissues. Particularly, IHC techniques are recommended for laboratories that have no facility for virus separation but equipped with histopathology techniques.
Acknowledgments This project was supported by Razi Vaccine and Serum Research Institute, Kerman Branch, Iran. The authors wish to express their gratitude to all who helped them.

\section{References}

Bhattacharjee PS, Naylor CJ, Jones RC (1994) A simple method for immunofluorescence staining of tracheal organ cultures for the rapid identification of infectious bronchitis virus. Avian Pathol 23:471-480

Cavanagh D, Naqi SA (2003) Infectious Bronchitis. In: Saif YM, H.J. Barnes, J.R. Glisson, A.M. Fadly, McDougald LR, Swayne DE (eds) Diseases of poultry. 11 edn. Iowa State Press, pp 101-119

Cavanagh D, Mawditt K, Britton P, Naylor C (1999) Longitudinal field studies of infectious bronchitis virus and avian pneumovirus in broilers using type-specific polymerase chain reactions. Avian pathol 28(6):593-605

Chauhan RS (1995) Text book of veterinary clinical and laboratory diagnosis. 1 edn. Jaypee Brothers

Chen BY, Hosi S, Nunoya T, Itakura C (1996) Histopathology and immunohistochemistry of renal lesions due infectious bronchitis virus in chicks. Avian Pathol 22:269-283

Cruz-Coy J, Giambrone J, Hoerr F (1993) Immunohistochemical detection of infectious bursal disease virus in formalin-fixed, paraffin-embedded chicken tissues using monoclonal antibody. Avian Diseases:577-581

Dabbas DJ (2002) Diagnostic immunohistochemistry. Churchill Livingstone

De Wit JJ (2000) Technical review: detection of infectious bronchitis virus. Avian Pathol 29:105-118

Dhinakar G, Jayakumar V, Thangavelu A, Koteeswaran A, Venugopalan AT (1998) Immunorheophoresis for the diagnosis of infectious bursa disease. Avian Dis 42:388-392

Fitzgerald S, Reed W, Langheinrich K, Porter A, Lumbert L (1994) A retrospective immunohistochemical study of type II avian adenoviral infection in turkey, pheasant, and chicken tissues. Avian Diseases: $78-85$

Guy JS, Barnes HJ, Smith LG, Breslin J (1997) Antigenic characterization of a turkey coronavirus identified in poult enteritis-and mortality syndrome-affected turkeys. Avian Diseases:583-590

Handberg K, Nielsen OL, Pedersen MW, Jorgensen PH (1999) Detection and strain differentiation of infectious bronchitis virus in tracheal tissues from experimentally infected chickens by reverse transcription-polymerase chain reaction. Comparison with an immunohistochemical technique. Avian Pathol 28:327-335

Hayat MA (2002) Microscopy, immunohistochemistry and antigen retrial methods for light and electron microscopy. Kluwer, Plenum, NY

Kant A, Koch G, van Roozelaar DJ, Kusters JG, Poelwijk FAJ, van der Zeijst BAM (1992) Location of antigenic sites defined by neutralizing monoclonal antibodies on the S1 avian infectious bronchitis virus glycopolypeptide. J Gen Virol 73:591-596

Levinson W, Jawetz. E (1998) Medical microbiology \& immunology examination \& board review. 6 edn. Appleton \& Lange

Liu X, Giambrone J, Hoerr F (2000) In situ hybridization, immunohistochemistry, and in situ reverse transcription-polymerase chain reaction for detection of infectious bursal disease virus. Avian Diseases:161-169

Lockaby S, Hoerr F, Ellis A, Yu M (1993) Immunohistochemical detection of Newcastle disease virus in chickens. Avian Diseases:433-437

McNulty M, Mackie D, Pollock D, McNair J, Todd D, Mawhinney K, Connor T, McNeilly F (1990) Production and preliminary 
characterization of monoclonal antibodies to chicken anemia agent. Avian Diseases:352-358

Momayez R, Bozorgmehrifard MH, Toroghi R, Vasfi-Marandi M, Shoshtari AH (2008) Cross-immunity study of two experimentally oil emulsion inactivated infectious bronchitis vaccines. Arch Razi Ins 63(2):1-9

Nakamura K, Gane K, Cook A, Otsuki K, Huggins MB, Gudith AF (1991) Comparative study of respiratory lesions in two chicken lines of different susceptibility infected with infectious bronchitis virus: histology, ultrastructure and immunohistochemistry. Avian Pathol 20:241-257

Naqi SA (1990) A monoclonal antibody-based immunoperoxidase procedure for rapid detection of infectious bronchitis virus uninfected tissues. Avian Dis 34:893-898

Owen R, Cowen B, Hattel A, Naqi S, Wilson R (1991) Detection of viral antigen following exposure of 1-day-old chickens to the Holland 52 strain of infectious bronchitis virus. Avian Pathol J WVPA 20(4):663

Shamsaddini-Bafti M, Vasfi-Marandi M, Pourbakhsh SA, Gharagozlo M, Bahmani-Nejad M, Khazraee-Nia P (2002) The use of indirect immunoperoxidase assay in diagnosis of type A(H9N2) Avian
Influenza virus antigen on frozen tissue sections. Arch Razi Ins 53(2):11-21

Shoushtari AH, Toroghi R, Momayez R, Pourbakhsh SA (2008) 793/B type, the predominant circulating type of avian infectious bronchitis viruses 1999-2004 in Iran: a retrospective study. Arch Razi Ins 63(1): $1-5$

Smyth JA, Moffett DA, McNulty MS, Todd D, Mackie DP (1993) A sequential histopathologic and immunocytochemical study of chicken anemia virus infection at 1 day of age. Avian Dis 37:324-338

Swayne D, Beck J, Perdue M, Brugh M, Slemons R (1996) Assessment of the ability of ratite-origin influenza viruses to infect and produce disease in rheas and chickens. Avian Diseases:438-447

Swayne DE, Glisson JR, Jackwood MW, Pearson JE, Reed WM (1998) A laboratory manual for the isolation and identification of avian pathogens. American Association of Avian Pathologists, Pennsylvania

Vasfi-Marandi M, Bozorgmehrifard MH (2001) Isolation and identification of infectious bronchitis viruses in chickens between 19972000 in Iran. J Facul Vet Med Univ Tehran 56(3):119-124 